\title{
Variations
}

Variations

Revue internationale de théorie critique

$23 \mid 2020$

Pour une gauche érotique

\section{La révolution sexuelle}

A propos d'une contradiction de Freud dans sa théorie de la culture (1936)

\section{Wilhelm Reich}

Traducteur : Alexander Neumann

\section{OpenEdition}

Journals

Édition électronique

URL : http://journals.openedition.org/variations/1503

DOI : 10.4000/variations. 1503

ISSN : 1968-3960

Éditeur

Les amis de Variations

Référence électronique

Wilhelm Reich, «La révolution sexuelle », Variations [En ligne], 23 | 2020, mis en ligne le 01 septembre 2020, consulté le 07 septembre 2020. URL : http://journals.openedition.org/variations/1503 ; DOI : https://doi.org/10.4000/variations. 1503

Ce document a été généré automatiquement le 7 septembre 2020

Les ami•e•s de Variations 


\title{
La révolution sexuelle
}

\author{
A propos d'une contradiction de Freud dans sa théorie de la culture \\ (1936)
}

\section{Wilhelm Reich}

Traduction : Alexander Neumann

\section{NOTE DE L'ÉDITEUR}

Le texte original de Wilhelm Reich fut publié sous le titre Die Sexualität im Kultuirkamp (1936) voir:

https://archive.org/stream/Reich_1936_Sexualitaet_im_Kulturkampf_2te_k/

Reich_1936_Sexualitaet_im_Kulturkampf_2te_k_djvu.txt (tous droits réservés)

1 Toute discussion mature sur les implications sociologiques de la psychanalyse exige d'abord de tirer au clair la question de savoir si la conception sociologique, qui est prêtée à Freud à partir de son oeuvre tardive, serait une conséquence directe et rectiligne de son approche clinique? Ou si, au contraire, pareille conception sociologique serait le résultat d'une rupture avec l'approche clinique, encouragée par une appropriation inachevée et trompeuse des observations cliniques, telle qu'elle s'étale dans les conclusions grotesques de disciples passés ou actuels, par exemple chez Roheim, Pfister, Müller-Braunschweig, Koinai, Laforgue et d'autres encore. Si nous parvenons à déceler un tel saut, une telle rupture au sein de la théorie clinique, puis à exposer la correspondance qui existe entre la conception clinique trompeuse et la doctrine sociologique, alors nous sommes en mesure de nommer la source des erreurs de la sociologie psychanalytique (une source d'erreurs similaires se trouve d'ailleurs dans la fausse équation entre individu et société). Dès le départ, Freud a défendu un point de vue philosophique selon lequel la formation des cultures dépend de la répression des pulsions ou du moins de l'abstinence pulsionnelle, ce qu'il a essayé d'illustrer par la maitrise $d u$ feu. Son idée fondamentale est que les performances culturelles sont le fruit d'une sublimation d'énergies sexuelles, ce qui veut dire que toute formation culturelle résulte pour une part de la répression sexuelle ou du 
refoulement de la sexualité. Aujourd'hui nous savons que cette vue est inexacte, car il existe de hautes cultures qui sont dépourvues de tout répression sexuelle, dotées d'une vie sexuelle libre. ${ }^{1}$

Cette théorie freudienne ne saurait expliquer toutes les formes culturelles et éducatives de l'humanité, mais elle est juste si l'on l'applique aux formes particulières du patriarcat, où la répression sexuelle sert de fondement à une psychologie des masses qui permet cette culture-là. Comment se fait-il que Freud s'est laissé tenter par une conception aussi générale? Ses conceptions politiques et philosophiques ne l'y ont certainement pas poussé, bien au contraire: certains de ses travaux précoces vont dans le sens d'une critique sociale et révolutionnaire par exemple l'article »kulturelle Sexualmoral«. Freud n'a pas persévéré sur ce chemin, mais a même commencé à se rebiffer contre de telles explorations qui ne seraient pas dans le centre de gravité de la psychanalyse, comme il l'a fait remarquer de vive voix. Mes propres essais de critique culturelle et de politique sexuelle furent l'occasion de premiers désaccords importants.

Lorsque Freud a examiné les mécanismes psychiques et les contenus de la vie subconsciente, il a trouvé que l'inconscient était empli de pulsions asociales et antisociales. Sa découverte peut être confirmée par toute personne qui veut bien se servir des méthodes analytiques appropriées. Le fantasme d'assassiner le père, et de posséder la mère à sa place, se retrouvent chez tous les hommes. Partout, l'on trouve des impulsions cruelles, tout juste réfrénées par un sentiment de culpabilité plus ou moins conscient. La plupart des femmes manifestent de puissantes intentions de castrer les hommes pour s'approprier le pénis, ou de l'incorporer sous une forme quelconque, par exemple en l'avalant. Le fait d'inhiber ces pulsions n'aboutit non seulement au conformisme social, mais provoque aussi une série de troubles psychiques si ces pulsions sont maintenues de manière subconsciente (par exemple du vomissement hystérique, que les chirurgiens tentent d'arrêter par des opérations gastriques). Le fantasme masculin cruel, visant à blesser la femme au cours du rapport sexuel, de la transpercer, de la poignarder, peut finir en diverses sortes d'impuissance s'il est freiné par la peur et la culpabilité, ou alors il constitue le motif du meurtre sexuel lorsque cette inhibition vient à manquer. L'intention subconsciente de manger ses propres excréments, ou ceux d'autres personnes, irrigue l'imaginaire inconscient d'un grand nombre d'humains de notre sphère culturelle, et cela indépendamment de leur appartenance de classe comme le montre l'analyse clinique. Les représentants idéologiques du "lien conjugal" et du "saint amour maternel" n'ont pas été amusés d'apprendre, grâce à la psychanalyse, que la tendresse exaltée d'une mère envers son enfant, ou d'une femme envers son époux, correspondent directement à l'ampleur des pulsions meurtrières qui sont en jeu. Nous serions en mesure de poursuivre cette énumération à souhait, mais nous allons plutôt retourner à notre sujet principal. La vie de l'inconscient, ou plutôt des éléments refoulés qu'elle contient, se nourrit en premier lieu de résidus d'attitudes enfantines envers l'environnement social immédiat, envers les parents, les frères et soeurs, etc. L'enfant est obligé de dépasser ces impulsions spontanées, afin d'accéder à une existence personnelle et culturelle. La plupart des êtres humains paient cependant cher ce dépassement, à un âge peu avancé, par l'apparition d'une névrose plus ou moins grave, qui entrave sérieusement leur capacité à travailler ou leur puissance sexuelle. Le diagnostic concernant la caractéristique asociale de l'inconscient s'avère juste ici, tout comme la nécessité de renoncer à des pulsions pour devenir capable de s'adapter à l'ordre social. La contradiction se 
perpétue cependant dans l'apparition de deux aspects du même problème: d'un côté l'enfant doit refouler ses pulsions naturelles pour accéder à la culture; de l'autre côté il incorpore une névrose, souvent pour satisfaire ses pulsions, mais qui handicape à son tour ses capacités culturelles, rendant caduc son adaptation sociale et le rendant tôt ou tard asocial de nouveau. Pour rendre cet être capable de s'adapter aux conditions sociales établies, il faut alors revenir sur ses refoulements, libérer ses pulsions; ce n'est là que la phase préparatoire de la convalescence, et non pas encore la guérison en ellemême, ce que Freud avait établi dès ses premiers travaux. Que faut-il désormais mettre à la place du refoulement des pulsions? Certainement pas les pulsions qui viennent d'être libérées de leur refoulement, puisque cela signifie l'incapacité à mener une existence autonome...

4 La littérature psychanalytique fourmille d'endroits qui reprennent le constat (qui est déjà devenu une idée incorporée dans la pratique bien entendu) que ce n'est certainement pas la simple découverte et accessibilité du subconscient qui engage un passage à l'acte, donc la prise en compte positive du subconscient n'implique pas la prise en charge de l'action qui pourrait en découler. Ici, le psychanalyste érige un principe qui s'applique à la vie tout comme à la situation clinique de la thérapie: Vous avez le droit et vous devez dire tout ce qui vous vient; mais cela n'implique pas que vous puissiez faire tout ce que vous voulez.

5 Pourtant, la question demeure entière de savoir ce qu'il doit se passer avec les pulsions auparavant refoulées, désormais libérées, au vu de leur portée que tout psychanalyste responsable doit mesurer. La recommandation psychanalytique logique était: sublimer et réprouver. Mais parmi la masse des patients, très peu s'avèrent capables de faire l'effort de sublimation qui serait nécessaire pour parvenir à la guérison, et par conséquent l'exigence sociale d'un renoncement aux pulsions revient par la fenêtre, sous la forme de la réprobation. Maintenant, la réprobation doit remplacer le refoulement. Cette recommandation est justifiée par le constat que pendant l'enfance, la seule manière d'endiguer les pulsions était de les refouler, au vu du Moi enfantin faible, alors que l'adulte dispose d'un Moi fort, capable de faire face aux pulsions par leur réprobation. Alors que cette règle est souvent invalidée par l'expérience clinique, mais elle demeure toujours en vigueur. Cette approche domine encore la pédagogie psychanalytique. Anna Freud la défend aussi, par exemple concernant la question de savoir ce que l'enfant devrait faire de ses pulsions, d'abord refoulées puis libérées? La réprobation accompagne toujours la sublimation; pour ainsi dire le "renoncement volontaire" aux pulsions se substitue au refoulement. Dans cette conception, l'individu accède à la culture et porte la culture grâce à l'ascèse et non plus au refoulement, un présupposé qui se complète par l'idée que la société fonctionne comme l'individu, donc le développement culturel de la société implique le renoncement aux pulsions. L'ensemble de la construction théorique semble évident, elle est louée par la grande majorité des analystes, et même de tous les défenseurs d'une conception abstraite de la culture, donc de tout ce qui compte dans la société bourgeoise. Car le remplacement du refoulement par la réprobation leur permet de conjurer un spectre, ce spectre si menaçant qui jeta le trouble lorsque Freud fit part de ses premières découvertes, celles qui établirent clairement que le refoulement sexuel rend malade, qu'il empêche de travailler et d'accéder à la culture. Le monde bourgeois était vent debout contre le naufrage annoncé de la moralité et de l'éthique, accusant Freud de plaider en faveur d'une pratique obscène, qu'il le veuille ou non, mettant en péril la culture, et ainsi de suite. Le prétendu anti-moralisme de Freud fut l'arme la plus tranchante de ses 
premiers ennemis. Le spectre dont il s'agit ne disparut qu'à partir du moment, où la théorie de la réprobation fut mise en place; jusqu'alors les assurances de Freud n'avaient pas fait grand effet, lui qui défendait la culture et affirmait que ses découvertes ne venaient pas la menacer. Le cliché persistant d'une prétendue "pansexualité" freudienne en porte encore la trace. À partir du moment, où la découverte des pulsions ne devait plus conduire à une pratique libérée, l'hostilité ouverte pouvait céder le pas à une acceptation partielle, car désormais il emportait peu si la "défense de la culture" était assuré par le refoulement ou par le renoncement, pourvu que l'un des deux remplisse le rôle du Cerbère qui empêche les démons de l'empire occulte de Hadès de remonter à la surface. Cette approche pouvait même passer pour un progrès aux yeux des défenseurs de la culture, dans ma mesure où le refoulement inconscient du mal était remplacé par un renoncement volontaire à la satisfaction du désir.

6 Comme la véritable éthique de toute formation culturelle ne réside pas dans son caractère asexuel, mais dans la maitrise des tentations sexuelles, un accord mutuel devenait possible de telle sorte que la psychanalyse si décriée devint elle-même une partie intégrante de la culture - hélas en renonçant à une pulsion, à savoir sa propre théorie des pulsions. Je regrette d'être obligée de détruire l'illusion à laquelle s'adonnent tous les participants: leurs accords comportent une erreur manifeste qui annule tout le contrat. Si l'erreur invalide leurs conclusions, elle n'entament en rien les observations de la psychanalyse, qui restent pleinement pertinentes; elles sont simplement restées inachevées, ou encore enfouies sous des formulations abstraites qui rendent opaques ses implications profondes.

\section{NOTES}

1. Voir W. Reich, Der Einbruch der Sexualmoral, Verlag Sex-Pol., 1934.

\section{INDEX}

Mots-clés : Théorie critique, Ecole de Francfort, libération sexuelle, Sigmund Freud, psychanalyse 